\title{
DESARROLLO Y DESEMPEÑO DE UN PROCESO DE BENEFICIADO EN SECO DE VARIEDADES AMARGAS DE QUINUA BASADO EN LA APLICACIÓN DE UN LECHO FLUIDIZADO DE TIPO SURTIDOR (LFTS)
}

\author{
Ramiro Escalera Vásquez, Carla Quiroga Ledezma y Luis Arteaga Weill
}

\section{RESUMEN}

Se ha desarrollado un proceso novedoso de beneficiado en seco de quinua, mediante el empleo de un lecho fluidizado de tipo surtidor (LFTS). Se estudiaron las características básicas de funcionamiento del lecho en la remoción de saponinas de 3 ecotipos amargos de quinua real provenientes de zonas productivas en los departamentos de Oruro y Potosí.

Se construyeron dos reactores de vidrio a escala laboratorio de 7,5 y $20 \mathrm{~cm}$ de diámetro y boquillas de 1,4 y $3,4 \mathrm{~mm}$ y un prototipo piloto de sección rectangular de $10 \mathrm{~cm}$ de ancho por $40 \mathrm{~cm}$ de alto y $40 \mathrm{~cm}$ de largo, con una sección angular en la parte inferior donde se instalaron boquillas con una distancia entre ejes de $10 \mathrm{~cm}$. Tanto los reactores de laboratorio como el reactor piloto, se alimentaron de aire a través de un compresor de $400 \mathrm{Lmin}^{-1}$ de capacidad, provisto de un medidor de flujo de 10-100 $\mathrm{Lmin}^{-1} \mathrm{y}$ de un filtro de humedad y aceite. Muestras de quinua fueron procesadas en estos equipos de acuerdo a un diseño experimental multifactorial, evaluándose el efecto de los factores: ecotipo, diámetro de reactor, diámetro de boquilla y altura de lecho sobre el porcentaje de remoción de saponinas, la calidad nutritiva (porcentaje de proteína), el porcentaje de pérdida de masa y el consumo específico de energía.

Los factores más preponderantes sobre la remoción de saponinas son el diámetro del lecho y el diámetro de la boquilla, seguidos del ecotipo, lográndose valores de saponinas mínimos $(0-0,02 \%)$, tanto para los ecotipos individuales como para sus mezclas, con la siguiente combinación: diámetro de boquilla 1,4-1,8 mm; diámetro de lecho 7,5-12,5 cm; altura de lecho de $12,5 \mathrm{~cm}$ y $30 \mathrm{~min}$ de tiempo. Ninguno de los factores estudiados tiene un efecto significativo sobre el contenido de proteínas y las pérdidas de masa.

En general, tanto la remoción de saponinas como la pérdida de masa ocurren a mayor velocidad durante los primeros minutos. Las saponinas extraídas durante la desaponificación se recuperan en su totalidad. Los ecotipos más resistentes a la fricción entre granos de quinua son: (1) Toledo de Salinas de G. Mendoza; (2) Blanca de Uyuni; (3) Blanca de Salinas de G. Mendoza; (4) Amarilla de Uyuni y (5) Rosada de Uyuni, en ese orden. El desempeño de remoción de saponinas del prototipo piloto de paredes planas y sección rectangular es similar al del lecho de sección circular operado bajo las condiciones óptimas. Sin embargo, en ambos casos, el consumo específico de energía eléctrica es alto cuando se utiliza un compresor a pistón comercial $(0,621 \mathrm{kWh} / \mathrm{kg}$ quinua procesada para prototipo piloto y $1,259 \mathrm{kWh} / \mathrm{kg}$ para condiciones óptimas de laboratorio). Como conclusión general se puede afirmar que la configuración del lecho fluidizado de tipo surtidor que no utiliza agua es idónea para la remoción de saponinas de diferentes variedades de quinua amarga en escala de laboratorio.

Palabras Clave: Quinua, Remoción de Saponinas, Lecho Fluidizado de Tipo Surtidor. 